\title{
Acerca de los laicos en México: Guadalajara
}

\section{Walter Alberto Calzato}

RENÉE DE LA TORRE, 2006

\section{La Ecclesia Nostra: El catolicismo desde} la perspectiva de los laicos. El caso de Guadalajara

Fondo de Cultura Económica, Centro de Investigaciones y Estudios Superiores en Antropología Social, México.

$\mathrm{B}$ orges, con un sutil acento de Swenderborg, solía decir que, en realidad, los libros y los temas buscan al lector y no al revés. Éstos, con vida propia, transitan los escaparates y esperan pacientemente al lector buscado, o simplemente saben depositarse en las manos sin que uno lo advierta. El texto de Renée de la Torre, sin excepciones, cumplió su cometido. Supo llegar en el momento justo, como to- do buen texto que sabe de sí mismo y cómo fue construido.

Por medio de una erudición asombrosa y con un manejo y equilibrio dignos de mencionarse, la autora de marras nos lleva de la mano y nos permite dilucidar cuál es el papel político, religioso y social de la laicidad en la historia de la Iglesia católica mexicana, específicamente de la arquidiócesis de Guadalajara, territorio con

\section{About Secularists in Mexico: Guadalajara}

WAlter Alberto Calzato: Colaborador en la Escuela Nacional de Antropología e Historia, México, D.F., y doctorado, Universidad de Buenos Aires, Argentina. wcalzato@yahoo.com.ar

Desacatos, núm. 28, septiembre-diciembre 2008, pp. 200-202.

\section{La Ecclesia Nostra:}

El catolicismo desde la perspectiva de los laicos. El caso de Guadalajara RENÉE DE LA TORRE

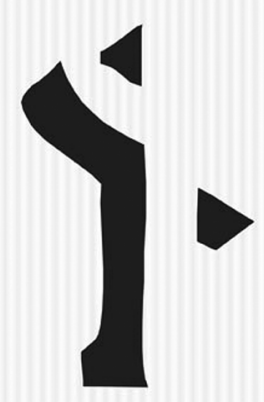

站

una catolicidad cualitativa y cuantitativamente relevante dentro del territorio mexicano, siendo uno de los baluartes donde se registra una muy fuerte identidad católica. Los movimientos laicos y su relación con el poder eclesiástico, su dialéctica entre el mundo secular y el mundo religioso, sus vaivenes, sus respuestas frente a la rigidez episcopal, son los temas centrales que nuestra autora desarrolla en su libro. 
Por lo general se piensa que la Iglesia católica romana es un poder supra verticalista que emana sus decisiones desde un arriba hacia un abajo de manera arbitraria. De la lectura de este libro surge cómo se construyó una profunda transversalidad entre el movimiento laical y las decisiones propias de la alta jerarquía católica con el vaivén de los cambios políticossociales, concretamente desde la encíclica Rerum novarum de 1890 -que tan bien entendió la catolicidad mexicana-y los trabajos de Acción Católica y de Pío XI, junto con la mayor parte de los movimientos laicales, y las respuestas al Concilio Vaticano II. Esta intersección, junto con el contexto político y social mexicano, que tanto afectó a la Iglesia, son la suma (sedimentación cultural shutziana, diría Osvaldo Soriano Núñez) de la identidad que ha construido la Iglesia en México. Me pregunto - y esto surge del diálogo con el texto objeto de análisissi realmente (tomando en cuenta el papel de los movimientos laicales en México, previos al Concilio Vaticano II, su fuerza, sus acciones, su papel relevante, su captación de la importancia de la acción social cristiana) la actividad laical se adelantó a la consagración de la vida seglar del Concilio mencionado (tomo en cuenta el sustrato de persecución política y de acoso, y no puedo dejar de pensar mientras escribo en aquel personaje de El bordo, de Sergio Galindo: un niño, en el Veracruz de 1934, que no puede asumir su identidad cuando la familia le pide rezar y en la escuela su maestra lo amonesta y ridiculiza cuando le dice que cree en Dios y que debe olvidarse de la reli-

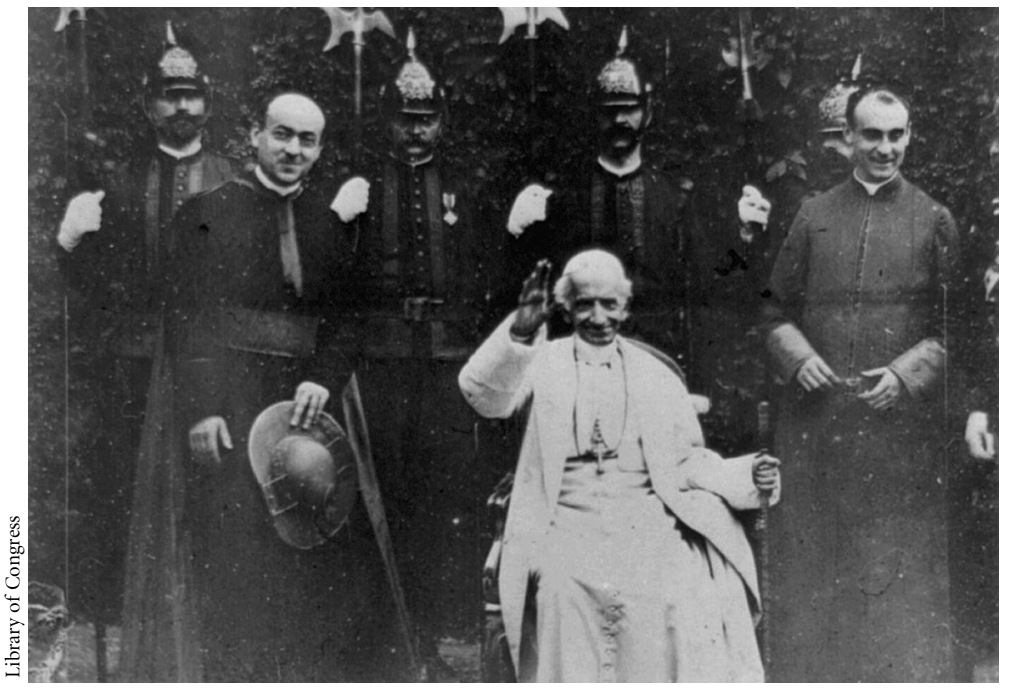

Papa León XIII, promotor de la encíclica Rerum novarum, ca. 1898.

gión y de Dios si quiere contribuir al progreso del país). Si se suma la profunda catolicidad mexicana (basta con mencionar Las tierras flacas, de Agustín Yáñez) a la lucha por poseer un espacio social determinado y el acoso político, esto de una u otra manera sembró y solidificó ese accionar, ese no quedarse quieto, ese modus vivendi que hizo que la Iglesia jamás depositara su ancla en algún puerto tentador. Las sillas en el camino cumplen esa función. No es aquí el caso.

Por supuesto que $-\mathrm{y}$ la autora es muy clara al respecto- - no todos los movimientos laicales son iguales. Tenemos desde un Opus Dei con un integrismo particular; los movimientos eclesiales de base, fruto de Medellín de 1968 y del Concilio Vaticano II (en algunos casos, un dolor de cabeza grande y profundo para la alta jerarquía católica en México); el Movimiento Familiar Cristiano, Pro Vida; la misma Teología de la Liberación y la opción por los pobres, entre tantos otros, que nacieron y desaparecieron, hasta la lucha por los derechos humanos, entre otros. Unos por la derecha y otros por la izquierda, son los que han conformado y conforman este profundo accionar dentro de la Ecclesia, la propia institución católica, presa de una prosapia romana y en buena parte con antiguas pretensiones de dominio universalistas, y la Nostra, el sustrato laico, aquellos que desde el llano, algunos con permiso eclesiástico y otros no tanto, contribuyeron y contribuyen a poner en equilibrio, no exento de tensión, las decisiones de las cúpulas episcopales. Aquellas voces que por lo bajo o por lo alto conforman el accionar de todos los días, los sentidos comunes de vida, que muchas veces no necesitan andamiajes teóricos, pero sí, como diría Ladislao Boros, decisión e historia.

La historia de la Iglesia católica en México ha transitado muchos cami- 


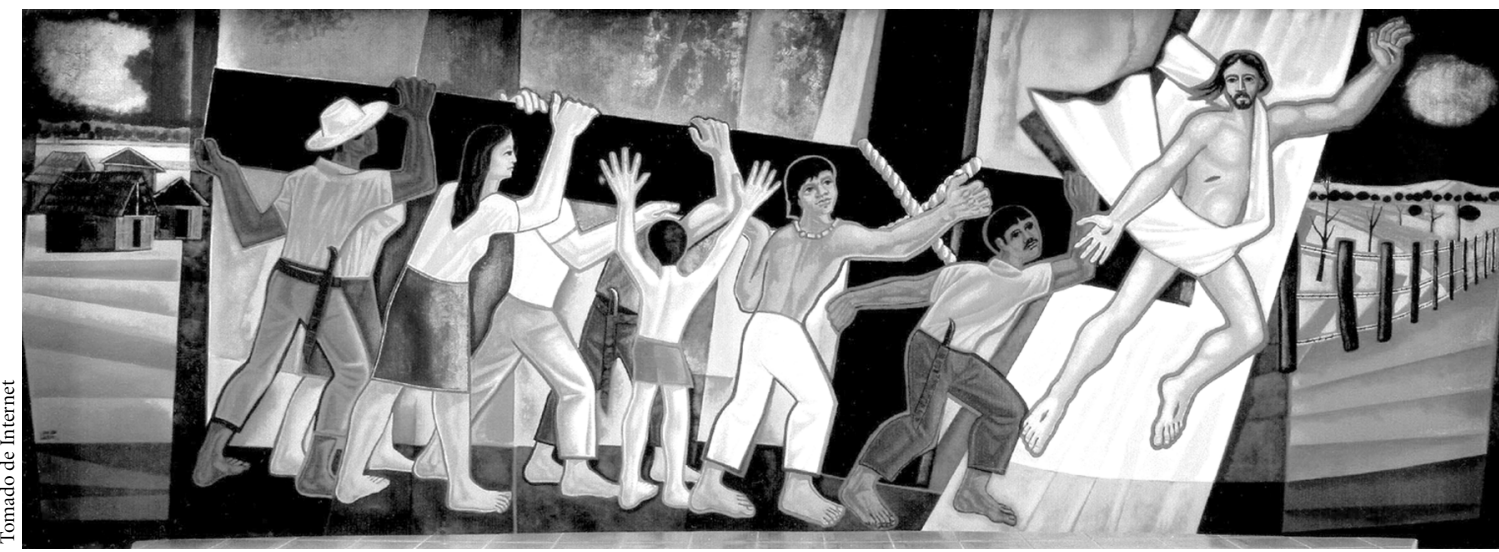

Mural en São Felix, Brasil.

nos y los movimientos laicales son parte intrínseca de su constitución. Tras la lectura de Ecclesia Nostra surgen muchas preguntas, aparecen muchas respuestas, se originan dudas, pero esto lo genera un texto que, con su profundidad - a la que podríamos calificar como estratigráfica一, nos conduce, tal arqueólogos del sentido que somos, a tomar la pala, nuestras escobillas e instrumentos de medición y seguir descubriendo las capas de ese enorme palimpsesto que conforman los avatares políticos, sociales, eclesiásticos y laicales de la nación mexicana. ¿No será que en el fondo los territorios que ocupamos y transitamos son solamente o nada más que geografías emocionales?

Borges construyó su literatura con bibliotecas infinitas y con muchos jardines de senderos que se bifurcan. La vida misma es un ancho y profundo camino, donde construimos, reconstruimos e interpretamos nuestras propias vicisitudes. Este libro nos lleva por ese sendero particular de la laicidad mexicana, de aquellos que toman como modelo de vida a la Iglesia católica, que interaccionan con ella, se vinculan y desvinculan, ora transitan su accionar, ora se repliegan en la secularidad quizás, en algunos casos, intransigente. Tal vez las herejías, junto con las voces (aquellas que se animan a hablar sobre la propia identidad católica) y las salidas (aquellos que se van, se convierten en ateos o transitan a otras religiones) —ambas categorías definidas por la autora - sean, entiendo, los cimientos, la argamasa de eso que llamamos Iglesia católica.

Todos estos acontecimientos marcaron a esta institución; se proyectó un perfil sobre ella y ella misma construyó una imagen que dar a ver. Pero como sucedió con aquella Teresa Batista cansada de la guerra, ese caminar entre la violencia y sus propios deseos la empujó a construir esa sedimentación que la nutre, la fortalece y, por momentos, la detiene. Fue tanto su accionar y su lucha que, al decir de Roberto Blancarte, la línea entre el poder político y la Iglesia transitó y transita en un espacio de sombras. Pero aquí la laicidad mexi- cana cumplió (y cumple) su papel como nexo entre ambas, sus interacciones, sus rebeliones, su perfil contestatario: es la carne y sangre que nutre.

Por fortuna estos senderos seguirán bifurcándose y la Iglesia continuará su camino en un mundo que se transforma día con día. No obstante, textos como el analizado aquí nos bastan para entender este presente y el pasado que lo alimenta. El revés de este libro deja en claro que la diversidad es el sustrato más profundo de todo sistema cultural, de todo movimiento llevado a cabo por el espíritu humano. La univosidad es un pecado muy grave. La dinámica no pertenece sólo a los discursos, sino que se encuentra en la profundidad de todo acontecer. Esta dinámica hace caso omiso del pensamiento. La historia no cesa; sabe, como decía André Gide, que lo que se piensa a sí mismo se detiene. Esto nos permite saborear, en un oscilar de pasado, presente y futuro, con muchísimo gusto, el texto que, de manera muy sucinta, acabamos de exponer.

Mayo 2007 